\title{
Two sides to colon cancer: mice mimic human anatomical region disparity in colon cancer development and progression
}

\author{
Jessica Felton ${ }^{1}$, Kunrong Cheng ${ }^{2}$, Aaron C. Shang ${ }^{2}$, Shien $\mathrm{Hu}^{2}$, Shannon M. Larabee ${ }^{1}$, Cinthia B. \\ Drachenberg $^{3}$, Jean-Pierre Raufman² \\ 'Department of Surgery, University of Maryland School of Medicine, Baltimore, MD 21201, USA. \\ ${ }^{2}$ Department of Medicine, University of Maryland School of Medicine, Baltimore, MD 21201, USA. \\ ${ }^{3}$ Department of Pathology, University of Maryland School of Medicine, Baltimore, MD 21201, USA.
}

Correspondence to: Jean-Pierre Raufman, Division of Gastroenterology \& Hepatology, Department of Medicine, University of Maryland School of Medicine, 22 S. Greene Street, N3W62, Baltimore, MD 21201, USA. Email: jraufman@som.umaryland.edu

How to cite this article: Felton J, Cheng K, Shang AC, Hu S, Larabee SM, Drachenberg CB, Raufman JP. Two sides to colon cancer: mice mimic human anatomical region disparity in colon cancer development and progression. J Cancer Metastasis Treat 2018;4:51. http://dx.doi.org/10.20517/2394-4722.2018.39

Received: 19 Jun 2018 First Decision: 6 Jul 2018 Revised: 14 Jul 2018 Accepted: 9 Aug 2018 Published: 27 Sep 2018

Science Editors: Lucio Miele Copy Editor: Cai-Hong Wang Production Editor: Huan-Liang Wu

\begin{abstract}
Aim: Strong evidence reveals important differences between cancers in the proximal vs, distal colon. Animal models of metastatic colon cancer are available but with varying degrees of reproducibility and several important limitations. We explored whether there were regional differences in the location of murine colon cancers and assessed the utility of murine models to explore the biological basis for such differences.
\end{abstract}

Methods: We re-analyzed data from our previous studies to assess the regional distribution of murine colon cancer. In survival surgery experiments, we injected HT-29 human colon cancer cells into the wall of the cecum or distal colon of $\mathrm{Nu}(\mathrm{NCr})-\mathrm{Foxn}^{\mathrm{nu}}$ or NOD.Cg-Prkdc $c^{\text {scid }} \mid 2 \mathrm{rg}^{\mathrm{Tim}}{ }^{\mathrm{Wii}} / \mathrm{SzJ}$ mice and compared the development of primary tumors and metastases.

Results: Within 7-17 weeks after intramural cecal injection of HT-29 cells, eight mice failed to develop solid primary tumors or metastases. In contrast, within four weeks after cell injection into the distal colon, 13 mice developed metastases - 12 mice developed subcutaneous metastases; of these, four developed liver metastases and one developed both liver and lung metastases. One mouse developed liver metastases only. Histological examination confirmed these lesions were adenocarcinomas.

Conclusion: Our findings reveal the preferential growth of murine colon neoplasia and invasive human orthotopic

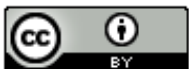

(C) The Author(s) 2018. Open Access This article is licensed under a Creative Commons Attribution 4.0 International License (https://creativecommons.org/licenses/by/4.0/), which permits unrestricted use, sharing, adaptation, distribution and reproduction in any medium or format, for any purpose, even commercially, as long as you give appropriate credit to the original author(s) and the source, provide a link to the Creative Commons license, and indicate if changes were made.

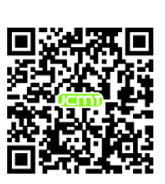


xenografts in the distal mouse colon. The new approach of injecting cells into the distal colon wall results in a pattern of colon cancer development that closely mimics the progression of metastatic colon cancer in humans. This novel model of colon neoplasia has great potential for exploring anatomical differences in colon cancer and testing novel therapeutics.

Keywords: Colorectal cancer, orthotopic tumor model, mouse model, HT-29 cells, colon

\section{INTRODUCTION}

In developed countries, colorectal cancer (CRC) is the second most common cause of cancer-related death in men and the third in women ${ }^{[1]}$. Metastatic cancer is the chief reason for CRC-related death; primary tumors without metastases are readily cured by endoscopic or surgical therapy ${ }^{[1]}$. Intriguingly, strong evidence reveals important differences between cancers in the proximal $v s$. distal colon ${ }^{[2-6]}$.

Compared to cancers of the distal colon, proximal colon cancers are more common in women, are associated with microsatellite instability and the serrated pathway, and are more likely to be at advanced stages when first diagnosed. Distal colon tumors are more likely to be associated with chromosomal instability and arise from the pathway involving dysregulated $A P C, K$-ras, DCC, and $p 53^{[6]}$. Previous studies reported conflicting findings with regards to whether mortality was significantly different in those with primary right- $v s$. leftsided colon cancer ${ }^{[--9]}$. A meta-analysis found higher mortality in patients with right-sided compared to leftsided colon cancer $^{[7]}$. A recent database study found that right-sided colon cancer was associated with lower cancer-specific mortality at the localization stage, equivalent mortality at the regional stage, and higher mortality at the metastatic stage ${ }^{[7]}$. Another recent retrospective study found those with left-sided colon cancer had better survival outcomes, especially with stage III cancers ${ }^{[10]}$. From 1998 to 2013 , the SEER (Surveillance, Epidemiology, and End Results) database identified 90,635 and 112,679 persons diagnosed with left- and right-sided colon cancer, respectively ${ }^{[7]}$.

Few therapeutics are either effective or available to treat persons with metastases to the liver and other organs. To improve therapeutic outcomes, there is great urgency to gain a better understanding of the mechanisms underlying colon cancer dissemination as a basis to develop targeted therapies. For investigators to test such new therapeutics with some degree of reliably there is also a great need to conceive and develop novel models that more closely mimic human disease.

Several animal models of metastatic colon cancer are available, with varying degrees of reproducibility, limitations, and imperfect fidelity to the biology of human cancer. Current murine models are limited by location, depending on what model is used, and cancers in different locations have different genetic profiles. A case in point is ApcMin mouse models that were meant to recapitulate defective Wnt/ $\beta$-catenin signaling present in $\sim 90 \%$ of human colon cancer ${ }^{[11]}$; in the most commonly used ApcMin mouse strains, tumors are almost uniformly adenomas, not adenocarcinomas, and are located predominantly in the small intestine, not colon. Also, murine models using injection of human colon cancer cells are limited by the need to use immune-deficient mice to allow tumors to develop, thus excluding the testing of immunotherapies ${ }^{[12]}$. Nonetheless, using syngeneic models with murine colon cancer cells is also imperfect because these cell lines are less well-studied and their biology may not mimic that of human cancers ${ }^{[12]}$.

Despite their limitations, murine models have long served as the most reliable platform for preclinical evaluation of new drugs and technologies ${ }^{[12]}$. These include models employing chemical carcinogenesis, genetic engineering, and animal- or patient-derived xenografts ${ }^{[1,13]}$; the latter have been particularly helpful to study the mechanisms underlying the metastatic spread of human colon cancer and identify susceptible therapeutic targets ${ }^{[1,12]}$. Colorectal cancer xenografts grown subcutaneously in immunodeficient mice are limited by the lack of metastasis; instead, orthotopic tumor models involving injection of CRC tumor cells or implanta- 
tion of tumor tissue directly into the wall of the colon have the potential to be more representative of human metastasis ${ }^{[14]}$.

We sought to determine if mice could serve as a model to explore regional differences in the location of cancers within the colon. To seek such differences in the growth and progression of colon neoplasia in mouse models, we first determined the location of colon tumors in mice treated with a colon-selective carcinogen or with a genetic predisposition to intestinal neoplasia. Next, based on our initial findings, we compared the proclivity of human colon cancer cells to grow and invade the proximal $v s$. distal colon of immune-deficient mice.

\section{METHODS}

\section{Analysis of the distribution of colon neoplasia in our published studies of chemically-induced carcinogenesis in mice}

To assess the regional distribution of murine colon cancer, we re-analyzed data from our published and unpublished murine colon cancer studies conducted from 2006 through $2018^{[15-19]}$. During this interval, we had treated 10- to 23-week-old male mice on a variety of genetic backgrounds with weekly intraperitoneal injections of $7.5 \mathrm{mg}$ azoxymethane (AOM)/kg body weight for 4 weeks. In C57BL/6 mice that are resistant to $\mathrm{AOM}$ treatment alone ${ }^{[20]}$, we supplemented the drinking water with $2.5 \%$ dextran sodium sulfate (DSS) for 5 days. We euthanized mice 20 weeks after the first AOM injection. An investigator masked to mouse genotype and treatments measured tumor number and size, and tumors were characterized as adenomas or adenocarcinomas based on size, contour, and color. A senior pathologist classified colon tumors as adenomas or adenocarcinoma based on consensus recommendations ${ }^{[21]}$.

\section{Surgical induction of colon neoplasia}

\section{Cell culture}

We purchased authenticated HT-29 cells from American type culture collection (ATCC). HT-29 cells were grown in McCoy's 5A medium (Life Technologies) supplemented with 10\% FBS. We grew cells in a humidified incubator at $37^{\circ} \mathrm{C}$ with $5 \% \mathrm{CO}_{2}$ and passaged weekly at subconfluence after trypsinization. We suspended cells in DPBS $\left(50 \times 10^{6} \mathrm{cell} / \mathrm{mL}\right)$ containing $10 \mu \mathrm{mol} / \mathrm{L}$ Y27632 and 50\% Matrigel.

\section{Animals}

All animal studies were conducted at the Baltimore VA Hospital Animal Facility and our laboratory in the Bressler Research Building at the University of Maryland School of Medicine. All surgical procedures were approved by the University of Maryland School of Medicine Institutional Animal Care and Use Committee under the Office of Animal Welfare Assurance. The Research and Development Committee at the Baltimore VA also approved animal studies. We used 11- to 14-week old male $\mathrm{Nu}\left(\mathrm{NCr}\right.$ )-Foxn $1^{\text {nu }}$ (nude) mice and NOD. Cg-Prkdc ${ }^{\text {scid }} \mathrm{I} 12 \mathrm{rg}^{\mathrm{Tim} 1 \mathrm{Wji}} / \mathrm{Sz}$ (NSG) mice, obtained from both the University of Maryland Veterinary Resources and Jackson Laboratories (Bar Harbor, ME).

\section{Surgical technique - laparotomy}

In a biosafety cabinet (BSL2) we anesthetized mice with continuous vaporized isoflurane for general anesthesia and performed laparotomy and cell injections with the mice on a warming pad. After confirming a sufficient level of anesthesia by a toe pinch, we positioned mice prone. For corneal protection, we applied lubricant (Major Pharmaceuticals LubriFresh P.M Ophthalmic Ointment, Livonia, MI) to each eye. We disinfected the mouse's upper back with an alcohol swab and administered buprenorphine SR (concentration $0.3 \mathrm{mg} / \mathrm{mL}$, dose $0.05-0.1 \mathrm{mg} / \mathrm{kg}$ body weight diluted 1:9 with sterile $0.9 \%$ saline) or carprofen (concentration $50 \mathrm{mg} / \mathrm{mL}$, dose $5 \mathrm{mg} / \mathrm{kg}$ body weight diluted 1:9 with sterile $0.9 \%$ saline) subcutaneously for analgesia. We then placed mice supine and, if necessary, clipped the anterior abdominal hair. After skin preparation with alcohol, to provide local anesthesia we injected mice subcutaneously with $0.25 \%$ bupivacaine (concentration $2.5 \mathrm{mg} / \mathrm{mL}$, dose $0.1 \mathrm{~mL}$ diluted 1:2 with sterile $0.9 \%$ saline) along the planned midline laparotomy site. Next, 
we cleansed the abdomen with povidine-iodine solution and alcohol and applied sterile drapes. We made a small midline laparotomy and inserted a self-retaining retractor in the upper abdomen.

Following injection of human colon cancer cells and replacing the intestines, we approximated fascial edges with 5-0 vicryl running sutures and closed the skin primarily with 4-0 nylon interrupted sutures. After applying skin glue ( $3 \mathrm{M}$ Vetbond tissue adhesive, St. Paul, MN) to the suture line, we awakened mice slowly from anesthesia and placed them in a clean cage for recovery with close monitoring. After completion of the operation, the mice were administered analgesia for at least $72 \mathrm{~h}$ post-operatively and monitored closely.

\section{Surgical technique - cecal injection}

To explore the predilection of human colon cancer cells to form tumors in different regions of the mouse, we first injected 2 to $5 \times 10^{6}(40-100 \mu \mathrm{L})$ HT-29 human colon cancer cells into the cecum of nude or NSG mice. We chose these cell numbers based on previous reports describing successful metastatic models of colon cancer in mice ${ }^{[1,12,22,23]}$. We described pre-operative steps above. The cecum was located using moist sterile cotton tip applicators and brought outside the abdomen onto a moist $2 \times 2$ sterile gauze. In all mice, we injected 2-5 $\times 10^{6}$ cells (40-100 $\left.\mu \mathrm{L}\right)$ into the wall of the cecum using a 27-guage needle. After injection, we applied light pressure at the injection site for approximately $30 \mathrm{~s}$ with a moist sterile tip applicator and inspected the area for leakage. We irrigated the cecum and abdominal cavity with warm DPBS, and then returned the cecum to its normal anatomic position within the abdomen. Closure of the abdomen was performed as describe above.

\section{Surgical technique - flank injection}

In mice failing to form cecal tumors, we confirmed the ability of the HT-29 cells to form xenografts and metastases following subcutaneous and splenic injection, respectively. For subcutaneous injections, we briefly anesthetized mice with vaporized isoflurane, disinfected their flanks with alcohol, and injected $2 \times 10^{6}$ cells $(40 \mu \mathrm{L})$ in each flank. We recovered mice from anesthesia in their cages.

\section{Surgical technique - splenic injection}

We described pre-operative steps above. The spleen was located using moist sterile cotton tip applicators and brought forward within the abdomen. In all mice, we injected $5 \times 10^{6}$ cells $(100 \mu \mathrm{L})$ into the wall of the spleen using a 27-guage needle. After injection, we applied light pressure at the injection site for approximately $30 \mathrm{~s}$ with a moist sterile tip applicator and inspected the area for leakage and bleeding. We irrigated the spleen and abdominal cavity with warm DPBS, and then returned the spleen to its normal anatomic position within the abdomen. After $1 \mathrm{~h}$, we removed the spleen and irrigated the abdomen again with DPBS. We closed the abdomen as described above.

\section{Surgical technique - distal colon injection}

To induce colon cancer growth and metastasis, we injected $5 \times 10^{6}(100 \mu \mathrm{L})$ HT-29 human colon cancer cells into the wall of the distal colon of nude or NSG mice. We described pre-operative steps above. The distal colon was located using moist sterile cotton tip applicators [Figure 1A]. In all mice, we injected $5 \times 10^{6}$ cells $(100 \mu \mathrm{L})$ into the wall of the distal colon using a 27-guage needle [Figure 1B]. After injection, we applied light pressure at the injection site for approximately $30 \mathrm{~s}$ with a moist sterile tip applicator [Figure $1 \mathrm{C}$ ] and inspected the area for leakage. We irrigated the distal colon and abdominal cavity with warm DPBS. We closed the abdomen as described above.

\section{Statistical analysis}

We used the unpaired Student's $t$ test (assuming unequal variance) to compare continuous variables between two independent groups. For multi-group comparisons, we applied two-way ANOVA with one betweensubject factor (WT vs. FGF15-deficient) and one within-subject factor (normal tissue vs. tumor tissue) followed by post hoc tests with Tukey-Kramer's adjustment for $P$ values. We used Fisher's exact test to compare 

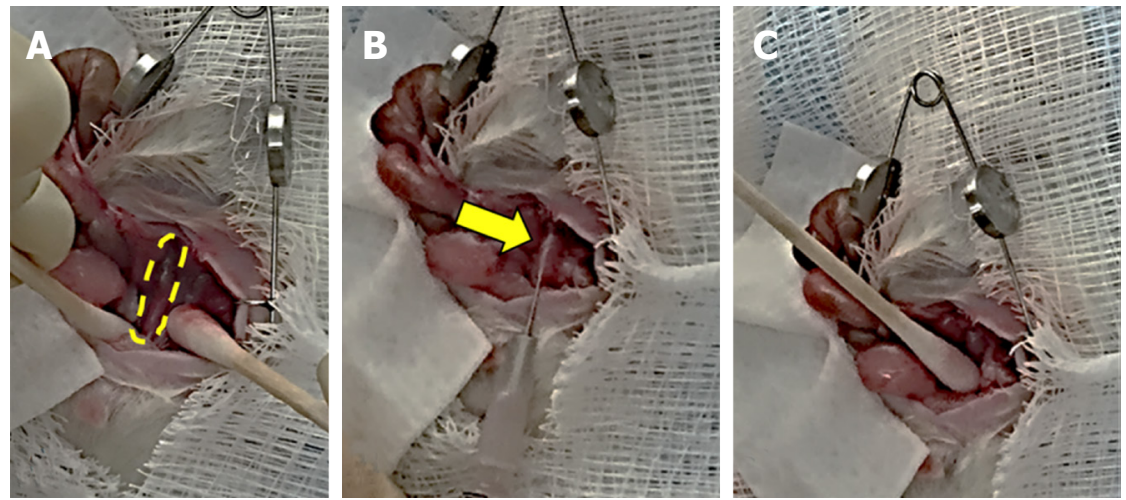

Figure 1. Main steps in the surgical approach to injecting colon cancer cells in the murine distal colon. A: Isolation of the distal colon (outlined) using moist sterile cotton tip applicators with retraction of the abdominal wall and evisceration of abdominal organs; B: injection of $5 \times 10^{6} \mathrm{HT}-29$ human colon cancer cells into the wall of the distal colon (arrow) using a 27-guage needle; C: applying pressure with a moist sterile cotton tip applicator at the injection site to prevent leakage and hemorrhage
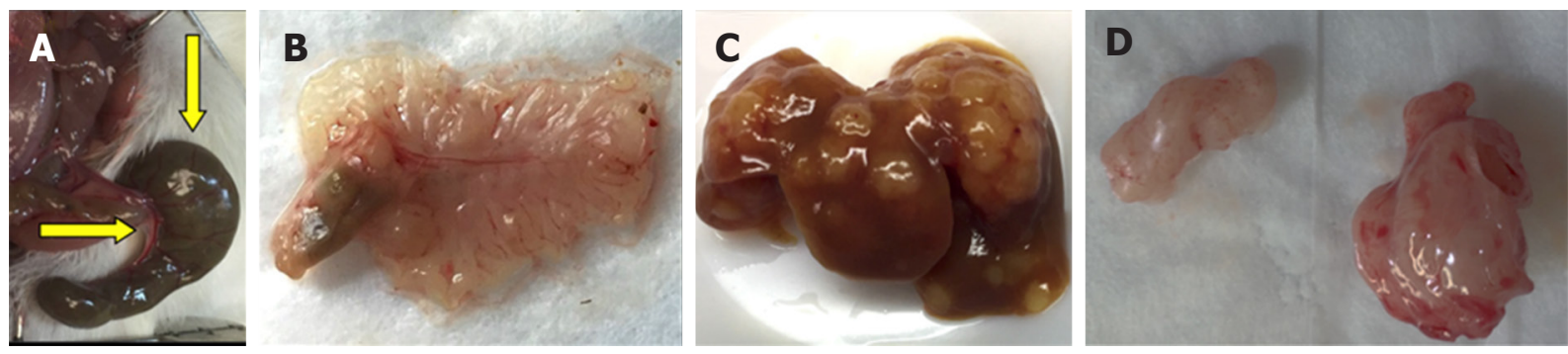

Figure 2. Results of cecal, splenic, and subcutaneous injections of HT-29 human colon cancer cells. A, B: Serosal and mucosal images of normal cecum 15 weeks after injecting HT-29 cells; C: numerous liver metastases 4 weeks after splenic injection; D: representative xenografts harvested from mouse flanks 4 weeks after subcutaneous flank injection

proportions. We considered differences significant when $\mathrm{P}$ was less than 0.05 .

\section{RESULTS}

\section{Chemical induction of colon cancer}

During a 12-year period, we induced colon neoplasia by treating 182 mice with AOM alone and 94 mice with AOM plus DSS. Strikingly, in all AOM- and AOM/DSS-treated mice that developed adenomas and adenocarcinomas [265 of 276 mice (96\%)], all tumors were limited to the distal half of the colon; no proximal lesions were present $(P<0.001)$. None of the 276 mice that developed primary colon tumors had metastases.

\section{Surgical induction of colon cancer}

\section{Cecal/flank/splenic injection}

Seven to 17 weeks after cecal injection of HT-29 cells, none of 8 mice (5 nude, 3 NSG) developed a cecal lesion [Figure 2A and B]. Yet, within 4 weeks, injecting HT-29 cells into the spleens and flanks of nude mice (3 mice each) uniformly yielded liver metastases [Figure 2C] and xenografts [Figure 2D], respectively, confirming the cells were capable of developing solid tumors that grew and metastasized. No metastases developed after flank injection and xenograft formation.

\section{Distal colon injection}

Within four weeks after cell injection, 12 mice developed primary colon tumor at the injection site in the distal colon and 13 mice (4 NSG, 9 nude) developed metastases [Table 1]. Based on our preliminary mouse experiments as well as the results of previously published studies ${ }^{[1,23,24]}$, we euthanized mice four weeks after cell injection. Twelve mice developed subcutaneous anterior abdominal metastases; of these, four developed 

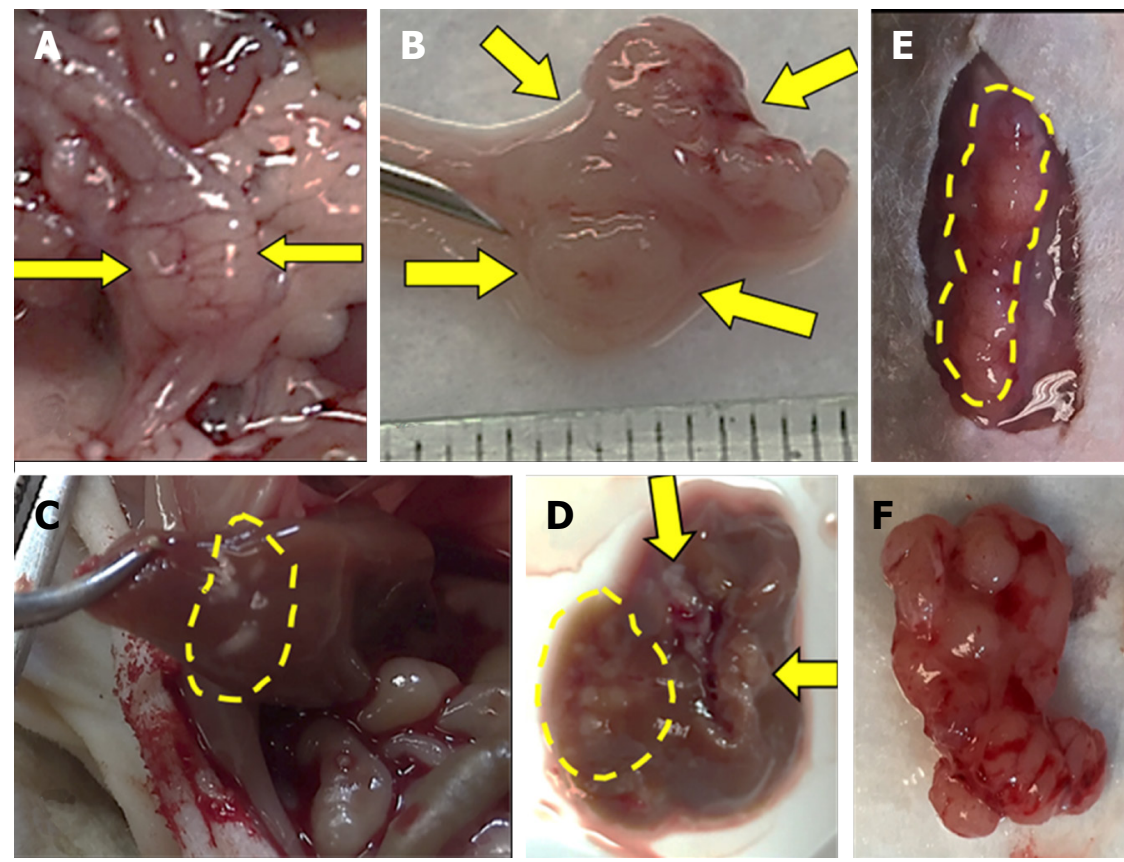

Figure 3. Injected human colon cancer cells form solid tumors in the distal colon with liver, lung, and anterior abdominal wall metastases. Serosal (A) and mucosal (B) images show invasive solid tumor in the distal colon (arrows). Metastases in the liver, in situ (C) and ex vivo (D) (arrows and dashed lines). Subcutaneous metastases in the anterior abdominal wall, in situ (E) and ex vivo (F).
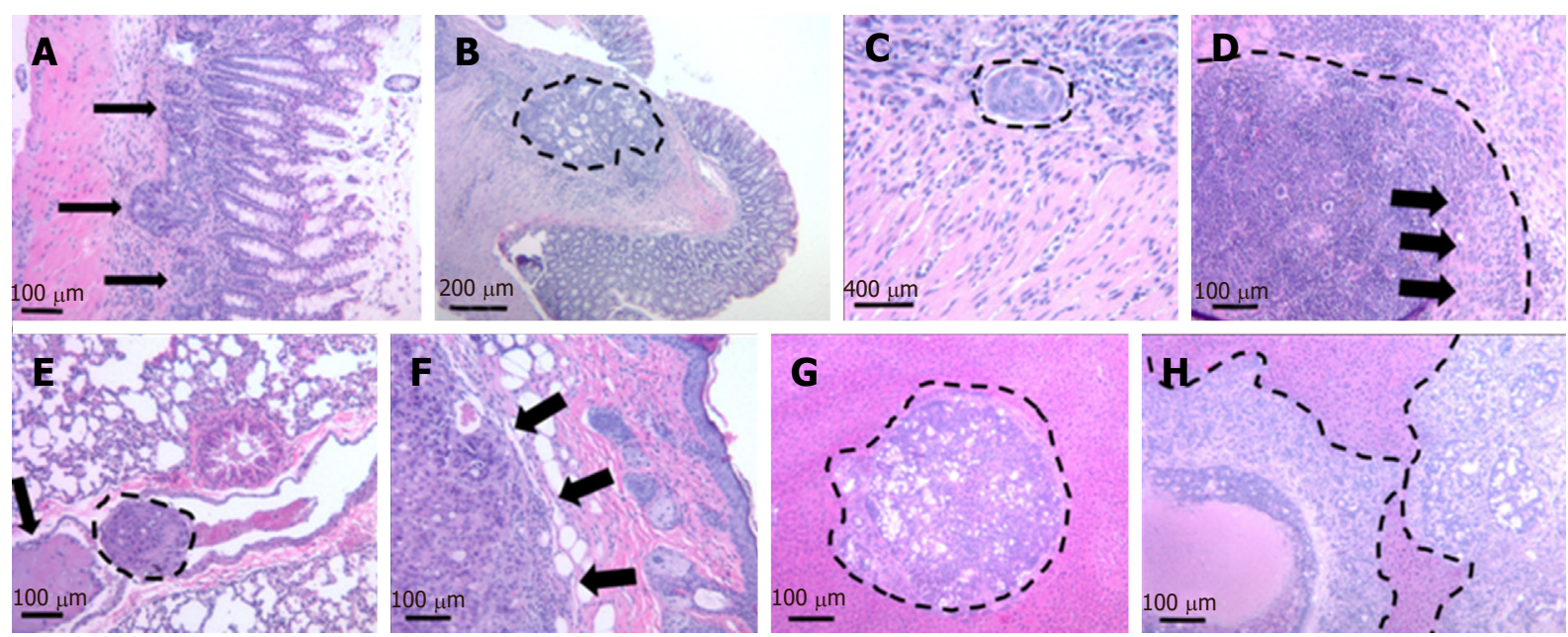

Figure 4. Representative histological images of local colon tumor as well as metastases to the lung, liver, and anterior abdominal wall. (A) and (B) Primary tumor invading the intestinal wall (arrows and dashed lines); C: tumor emboli in intramural and subserosal lymphatics (dashed lines); D: lymph node infiltration. Dashed lines delineate lymph node capsule, arrows indicate tumor cells; E: metastasis to the lung: intravascular tumor embolus (dashed lines) and thrombus (arrow); F: subcutaneous metastasis to anterior abdominal wall (arrows) with epidermis to the right; $\mathrm{G}$ and $\mathrm{H}$ : multiple metastatic tumor deposits within the liver (dashed lines).

liver metastases and one developed both liver and lung metastases [Figure 3]. One mouse developed liver metastases only. Histological examination confirmed the presence of adenocarcinoma within the wall of the mouse colon [Figures $4 \mathrm{~A}$ and $\mathrm{B}$ ], in the lymphatic spaces [Figures $4 \mathrm{C}$ and $\mathrm{D}$ ], in the lung parenchyma [Figure $4 \mathrm{E}$ ], in the anterior abdominal wall [Figure $4 \mathrm{~F}$ ], and multiple metastatic deposits within the liver [Figures $4 \mathrm{G}$ and $\mathrm{H}$ ].

\section{DISCUSSION}

Increasing evidence supports the presence of major differences in right- and left-sided colon cancers with regard to the host's clinical characteristics, microbiome, response to treatment and outcome. Although mo- 
Table 1. Distribution of primary colon tumors and metastases after injection of human colon cancer cells into the distal colon wall of 13 mice

\begin{tabular}{llcccc}
\hline Mouse & Strain & Primary colon tumor & Liver metastases & Abdominal wall metastases & Lung metastases \\
\hline 1 & NSG & $\sqrt{ }$ & - & $\sqrt{ }$ & - \\
2 & NSG & $\sqrt{ }$ & - & $\sqrt{ }$ & - \\
3 & NSG & $\sqrt{ }$ & - & $\sqrt{ }$ & - \\
4 & NSG & $\sqrt{ }$ & - & $\sqrt{ }$ & - \\
5 & Nude & $\sqrt{ }$ & - & $\sqrt{ }$ & - \\
6 & Nude & $\sqrt{ }$ & $\sqrt{ }$ & $\sqrt{ }$ & - \\
7 & Nude & $\sqrt{ }$ & $\sqrt{ }$ & $\sqrt{ }$ & - \\
8 & Nude & - & - & $\sqrt{ }$ & - \\
9 & Nude & $\sqrt{ }$ & - & $\sqrt{ }$ & - \\
10 & Nude & $\sqrt{ }$ & $\sqrt{ }$ & $\sqrt{ }$ \\
11 & Nude & $\sqrt{ }$ & $\sqrt{ }$ & $\sqrt{ }$ & - \\
12 & Nude & $\sqrt{ }$ & $\sqrt{ }$ & - & - \\
13 & Nude & $\sqrt{ }$ & $\sqrt{ }$ & & \\
\hline
\end{tabular}

NSG: NOD.Cg-Prkdc ${ }^{\text {scid }} \mid 2 \mathrm{rg}^{\mathrm{Tim} i W_{\mathrm{ji}}} / \mathrm{SzJ}$.

lecular and genetic profiling of cancer cells has revealed some important differences, the reasons for this anatomical disparity remain unclear ${ }^{[25,26]}$. Whether the primary tumor is located in the right or left colon has been reported to play a prognostic role in metastatic colorectal cancer ${ }^{[25]}$, although new findings suggest primary tumor 'sidedness' may be a less important determinant of overall and disease-specific survival than patient characteristics and other pathological features ${ }^{[26]}$.

Our studies reveal that mice appear to be a suitable model to explore the predilection of cancer for different anatomical regions of the colon. We found that mice treated with a colon-selective carcinogen or with a genetic predisposition to intestinal neoplasia developed tumors only in the distal half of the colon; there were no proximal lesions. Likewise, immune-deficient mice preferentially developed colon cancer and metastases when we injected HT-29 human colon cancer cells into the distal, rather than proximal, colon.

In the course of these studies, we developed a novel method for inducing metastatic colon cancer in mice. We chose HT-29 cells for our studies because they a are commonly used in vitro model of human colon cancer and express M3 type muscarinic receptors (M3R), a focus of our research program ${ }^{[27-29]}$. Injecting HT-29 human colon cancer cells between the mucosa and the muscularis external layers of the distal colon wall of immunodeficient mice resulted in a pattern of tumor dissemination that mimicked human disease. Nonetheless, while it is uncommon for colon cancer in humans to spread to the skin and subcutaneous tissues, we found that when injected in mice, HT-29 cells are capable of diffuse metastasis, including to the skin. At present, we cannot explain why these colon cancer cells had a predilection for the anterior abdominal subcutaneous tissue. The location of these skin metastases near the surgical incision site leads us to speculate that features of the inflammatory response to the skin incision (e.g., release of cytokines) may attract migrating colon cancer cells to this location, a testable hypothesis that may expand our understanding of the biology underlying tumor metastasis. We will test this hypothesis in future studies.

We believe this novel animal model will be an important adjunct to our in vitro studies and useful to study and test novel therapies that target $\mathrm{M} 3 \mathrm{R}$ and its downstream signaling pathways to attenuate cancer cell dissemination. This model is relatively straightforward and the procedures easy to learn and perform by an investigator experienced in animal surgery, with reasonably rapid development of primary solid tumors and metastases. Unlike xenograft models, this method requires only one mouse and one operation to generate both colon cancer and metastasis. Our approach appears more biologically relevant than models in which investigators inject cells into the tail vein or footpad. 
An important limitation of our new approach is that, as discussed in the Introduction, colon cancer immunotherapy cannot be studied in models using immune-deficient mice. However, humanizing the mouse immune system may achieve this goal. Next-generation models, including "immunoavatar mice" could offer the ability to study the effects of immunotherapy in colon cancer. Hemato-lymphoid humanized mouse models may allow the development of a complete human immune system in a human tumor-bearing mouse $^{[30]}$. Yet, even these humanized models are likely to present important obstacles with regard to mimicking the physiological maturation of human immune cells and the progression of human colon cancer.

In conclusion, our findings identify preferential growth of murine colon neoplasia and invasive human orthotopic xenografts in the distal mouse colon. These data support the utility of mouse models to study anatomical variance in the development and progression of colon neoplasia. We describe a useful model for inducing metastatic colon cancer in mice that is neither laborious nor time-consuming. This novel approach furnishes animals that closely mimic the progression of metastatic colon cancer in humans. This approach shows promise for studying novel therapeutics targeting colon cancer dissemination and metastasis.

\section{DECLARATIONS}

\section{Authors' contributions}

Study Design: Felton J, Cheng K, Raufman JP

Experimental Methods: Felton J, Cheng K, Shang AC, Hu S, Drachenberg CB, Raufman JP

Manuscript Preparation: Felton J

Final Review: Felton J, Raufman JP

Manuscript Review: Cheng K, Shang AC, Hu S, Larabee SM, Drachenberg CB, Raufman JP

\section{Availability of data and materials}

Not applicable.

\section{Financial support and sponsorship}

This work was supported by VA Merit Award BX002129 (JPR) from the United States (U.S.) Department of Veterans Affairs Biomedical Laboratory Research and Development Program. The contents do not represent the views of the U.S. Department of Veterans Affairs or the United States Government. Jessica Felton and Shannon Larabee were supported by T32 DK067872.

\section{Conflicts of interest}

All authors declared that there are no conflicts of interest.

\section{Ethical approval and consent to participate}

Not applicable.

\section{Consent for publication}

Not applicable.

\section{Copyright}

(c) The Author(s) 2018.

\section{REFERENCES}

1. Lee WY, Hong HK, Ham SK, Kim CI, Cho YB. Comparison of colorectal cancer in differentially established liver metastasis models. Anticancer Res 2014;34:3321-8.

2. Iacopetta B. Are there two sides to colorectal cancer? Int J Cancer 2002;101:403-8.

3. Sugai T, Habano W, Jiao YF, Tsukahara M, Takeda Y, Otsuka K, Nakamura S. Analysis of molecular alterations in left- and right-sided colorectal carcinomas reveals distinct pathways of carcinogenesis: proposal for new molecular profile of colorectal carcinomas. J Mol Diagn 
2006;8:193-201.

4. Azzoni C, Bottarelli L, Campanini N, Di Cola G, Bader G, Mazzeo A, Salvemini C, Morari S, Di Mauro D, Donadei E, Roncoroni L, Bordi C, Sarli L. Distinct molecular patterns based on proximal and distal sporadic colorectal cancer: arguments for different mechanisms in the tumorigenesis. Int J Colorectal Dis 2007;22:115-26.

5. Watanabe T, Kobunai T, Toda E, Yamamoto Y, Kanazawa T, Kazama Y, Tanaka J, Tanaka T, Konishi T, Okayama Y, Sugimoto Y, Oka T, Sasaki S, Muto T, Nagawa H. Distal colorectal cancers with microsatellite instability (MSI) display distinct gene expression profiles that are different from proximal MSI cancers. Cancer Res 2006;66:9804-8.

6. Benedix F, Kube R, Meyer F, Schmidt U, Gastinger I, Lippert H, Group CRCPTS. Comparison of 17,641 patients with right- and left-sided colon cancer: differences in epidemiology, perioperative course, histology, and survival. Dis Colon Rectum 2010;53:57-64.

7. Wang C, Wainberg ZA, Raldow A, Lee P. Differences in cancer-specific mortality of right- versus left-sided colon adenocarcinoma: a surveillance, epidemiology, and end results database analysis. JCO Clinical Cancer Informatics 2017;1:1-9.

8. Meguid RA, Slidell MB, Wolfgang CL, Chang DC, Ahuja N. Is there a difference in survival between right- versus left-sided colon cancers? Ann Surg Oncol 2008;15:2388-94.

9. Weiss JM, Pfau PR, O’Connor ES, King J, LoConte N, Kennedy G, Smith MA. Mortality by stage for right- versus left-sided colon cancer: analysis of surveillance, epidemiology, and end results--Medicare data. J Clin Oncol 2011;29:4401-9.

10. Lim DR, Kuk JK, Kim T, Shin EJ. Comparison of oncological outcomes of right-sided colon cancer versus left-sided colon cancer after curative resection: which side is better outcome? Medicine (Baltimore) 2017;96:e8241.

11. Polakis P. The oncogenic activation of beta-catenin. Curr Opin Genet Dev 1999;9:15-21.

12. Terracina KP, Aoyagi T, Huang WC, Nagahashi M, Yamada A, Aoki K, Takabe K. Development of a metastatic murine colon cancer model. J Surg Res 2015;199:106-14.

13. Golovko D, Kedrin D, Yilmaz Ö, Roper J. Colorectal cancer models for novel drug discovery. Expert Opin Drug Discov 2015;10:1217-29.

14. Flatmark K, Maelandsmo GM, Martinsen M, Rasmussen H, Fodstad Ø. Twelve colorectal cancer cell lines exhibit highly variable growth and metastatic capacities in an orthotopic model in nude mice. Eur J Cancer 2004;40:1593-8.

15. Cheng K, Metry M, Felton J, Shang AC, Drachenberg CB, Xu S, Zhan M, Schumacher J, Guo GL, Polli JE, Raufman JP. Diminished gallbladder filling, increased fecal bile acids, and promotion of colon epithelial cell proliferation and neoplasia in fibroblast growth factor 15-deficient mice. Oncotarget 2018;9:25572-85.

16. Cheng K, Xie G, Khurana S, Heath J, Drachenberg CB, Timmons J, Shah N, Raufman JP. Divergent effects of muscarinic receptor subtype gene ablation on murine colon tumorigenesis reveals association of M3R and zinc finger protein 277 expression in colon neoplasia. Mol Cancer 2014;13:77.

17. Raufman JP, Shant J, Xie G, Cheng K, Gao XM, Shiu B, Shah N, Drachenberg CB, Heath J, Wess J, Khurana S. Muscarinic receptor subtype-3 gene ablation and scopolamine butylbromide treatment attenuate small intestinal neoplasia in Apcmin/+ mice. Carcinogenesis 2011;32:1396-402.

18. Raufman JP, Dawson PA, Rao A, Drachenberg CB, Heath J, Shang AC, Hu S, Zhan M, Polli JE, Cheng K. Slc10a2-null mice uncover colon cancer-promoting actions of endogenous fecal bile acids. Carcinogenesis 2015;36:1193-200.

19. Raufman JP, Samimi R, Shah N, Khurana S, Shant J, Drachenberg C, Xie G, Wess J, Cheng K. Genetic ablation of M3 muscarinic receptors attenuates murine colon epithelial cell proliferation and neoplasia. Cancer Res 2008;68:3573-8.

20. Dougherty U, Cerasi D, Taylor I, Kocherginsky M, Tekin U, Badal S, Aluri L, Sehdev A, Cerda S, Mustafi R, Delgado J, Joseph L, Zhu H, Hart J, Threadgill D, Fichera A, Bissonnette M. Epidermal growth factor receptor is required for colonic tumor promotion by dietary fat in the azoxymethane/dextran sulfate sodium model: roles of transforming growth factor-\{alpha\} and PTGS2. Clin Cancer Res 2009;15:67809.

21. Boivin GP, Washington K, Yang K, Ward JM, Pretlow TP, Russell R, Besselsen DG, Godfrey VL, Doetschman T, Dove WF, Pitot HC, Halberg RB, Itzkowitz SH, Groden J, Coffey RJ. Pathology of mouse models of intestinal cancer: consensus report and recommendations. Gastroenterology 2003;124:762-77.

22. Céspedes MV, Espina C, García-Cabezas MA, Trias M, Boluda A, Gómez del Pulgar MT, Sancho FJ, Nistal M, Lacal JC, Mangues R. Orthotopic microinjection of human colon cancer cells in nude mice induces tumor foci in all clinically relevant metastatic sites. Am J Pathol 2007; 170:1077-85.

23. Hackl C, Man S, Francia G, Milsom C, Xu P, Kerbel RS. Metronomic oral topotecan prolongs survival and reduces liver metastasis in improved preclinical orthotopic and adjuvant therapy colon cancer models. Gut 2013;62:259-71.

24. Hite N, Klinger A, Hellmers L, Maresh GA, Miller PE, Zhang X, Li L, Margolin DA. An optimal orthotopic mouse model for human colorectal cancer primary tumor growth and spontaneous metastasis. Dis Colon Rectum 2018;61:698-705.

25. Stintzing S, Tejpar S, Gibbs P, Thiebach L, Lenz HJ. Understanding the role of primary tumour localisation in colorectal cancer treatment and outcomes. Eur J Cancer 2017;84:69-80.

26. Leijssen LGJ, Dinaux AM, Kunitake H, Bordeianou LG, Berger DL. Pathologic factors are more important than tumor location in long-term survival in colon cancer. Int J Colorectal Dis 2018;33:709-17.

27. Kopp R, Lambrecht G, Mutschler E, Moser U, Tacke R, Pfeiffer A. Human HT-29 colon carcinoma cells contain muscarinic M3 receptors coupled to phosphoinositide metabolism. Eur J Pharmacol 1989;172:397-405.

28. Belo A, Cheng K, Chahdi A, Shant J, Xie G, Khurana S, Raufman JP. Muscarinic receptor agonists stimulate human colon cancer cell migration and invasion. Am J Physiol Gastrointest Liver Physiol 2011;300:G749-60.

29. Raufman JP, Cheng K, Saxena N, Chahdi A, Belo A, Khurana S, Xie G. Muscarinic receptor agonists stimulate matrix metalloproteinase 1-dependent invasion of human colon cancer cells. Biochem Biophys Res Commun 2011;415:319-24.

30. Sanmamed MF, Chester C, Melero I, Kohrt H. Defining the optimal murine models to investigate immune checkpoint blockers and their combination with other immunotherapies. Ann Oncol 2016;27:1190-8. 